\title{
Alergia a proteína de leche de vaca en el menor de un año
}

\author{
ISABEL MIQUEL E. ${ }^{1}$, M. EUGENIA ARANCIBIA S. ${ }^{1}$
}

1. Unidad de Gastroenterología Infantil. Departamento. de Pediatría. Clínica Alemana de Santiago.

\begin{abstract}
Allergy to dairy protein in children under one year old

Food allergies are defined as an immune reaction to a food protein. It may be mediated by IgE antibodies or not, or by mixed mechanisms. During the first year of life, allergy to dairy products is the most frequent cause of food allergy. This paper reviews mechanisms and management of allergy to dairy products.

(Key words: Food Alergy, Dairy Protein, IgE, Infant).

Rev Chil Pediatr 2012; 83 (1): 78-83

\section{RESUMEN}

Se define alergia alimentaria como una reacción adversa que se produce frente a la exposición de un alimento, mediada por una respuesta inmune específica y reproducible ${ }^{1}$. La alergia alimentaria puede ser mediada por anticuerpos de tipo IgE, por mecanismos mixtos o no mediada por IgE. Durante el primer año de vida la alergia a la proteina de leche de vaca (APLV) es la forma más frecuente de presentación de la alergia alimentaria². Esta revisión pretende entregar una propuesta al enfrentamiento clínico de un lactante menor de un año con sospecha de APLV.
\end{abstract}

(Palabras clave: Alergia alimentaria, Proteina de leche de vaca, Inmunoglobulina E, Lactante).

Rev Chil Pediatr 2012; 83 (1): 78-83

\section{Epidemiología}

En Chile no contamos con estudios de prevalencia de esta patología. Diversos estudios prospectivos europeos han estimado un rango de 1,9 a 4,9\% APLV en lactantes menores de un año $0^{3,4}$.

\section{Sospecha diagnóstica APLV}

Esta patología no sólo afecta al paciente, sino también a todo su grupo familiar y entorno social ${ }^{5}$. Frente a la sospecha de una APLV, una historia clínica completa y un examen físico acucioso son fundamentales para el diag-

Trabajo recibido el 16 de octubre de 2011, aceptado para publicación el 12 de enero de 2012.

Correspondencia a:

Isabel Miquel E.

imiquel@alemana.cl 
nóstico. En la historia clínica son de importancia la edad de inicio, el tipo de síntomas y su frecuencia, tiempo entre la ingestión y el inicio de los síntomas, detalles del tipo de alimentación (leche materna o fórmula) y antecedentes de atopia personal y familiar ${ }^{6}$. El riesgo de atopia en un paciente aumenta si uno de los padres o hermano gemelar tienen enfermedad atópica (20-40\% y $25-35 \%$ respectivamente). Este riesgo aumenta aún más si ambos padres son atópicos $(40-60 \%)^{7,8}$.

Se ha demostrado que la alimentación con lactancia materna exclusiva durante los primeros 4 a 6 meses de vida reduce el riesgo de APLV y de la mayoría de las manifestaciones de alergia severa durante el período de lactante $^{9}$.

No existen síntomas ni signos patognomónicos de APLV y el diagnóstico diferencial dependerá de los órganos afectados. La mayoría de las veces los síntomas ocurren luego de las primeras semanas de introducción de leche de vaca. Los órganos blanco son: aparato digestivo (50-60\%), piel (50-60\%) y tracto respiratorio (20-30\%) pudiendo comprometer más de un órgano en un número considerable de $\operatorname{casos}^{10}$. La frecuencia de anafilaxia se estima entre 0,8 a $9 \%$.

Además del órgano blanco, las manifestaciones clínicas dependerán del tipo de reacción inmunológica involucrada, pudiendo ser reacciones de tipo inmediato mediadas por IgE, mixtas o tardías mediadas por un mecanismo celular.

La reacción inmediata más severa es la anafilaxia, se produce minutos hasta dos horas post exposición al alergeno. Se caracteriza por compromiso súbito de piel y/o mucosas, con uno o más síntomas respiratorios (disnea, broncoespamo, estridor, hipoxemia), además síntomas cardiovasculares (hipotensión, sincope), síntomas gastrointestinales (vómitos, cólicos) y shock. Las reacciones inmediatas gastrointestinales incluyen el síndrome de alergia oral y alergia gastrointestinal inmediata (caracterizada clínicamente por vómitos). Las reacciones respiratorias incluyen: asma y rinitis secundaria a la ingestión o inhalación de leche de vaca. Las reacciones dermatológicas inmediatas son: eritema, angioedema, urticaria.
Los niños con sospecha de haber presentado una manifestación inmediata deben ser derivados al inmunólogo.

Los pacientes con reacciones tardías por proteína leche de vaca desarrollan síntomas desde horas a varios días después de la ingestión, siendo las manifestaciones más frecuentes gastrointestinales o dermatológicas.

En este tipo de reacción la presentación clínica varía desde formas leves y moderadas a casos severos, lo que determinará el manejo sugerido en cada paciente.

El enfrentamiento clínico y manejo dependerá de la forma de presentación (leve-moderada o severa) y del tipo de alimentación (leche materna o fórmula).

\section{Sospecha de APLV en niños alimentados con leche materna exclusiva}

$\mathrm{Al}$ evaluar a un lactante con sospecha APLV alimentado exclusivamente con leche materna se debe preguntar antecedentes de alergia familiar y realizar una historia y examen físico exhaustivo. Según los síntomas que presente el paciente definimos dos subgrupos:

\section{a) Sospecha de APLV leve o moderada con uno o más de los siguientes síntomas}

- Gastrointestinal: regurgitaciones frecuentes, vómitos, diarrea, rectorragia, constipación (con o sin eritema perianal).

- Piel: dermatitis atópica.

- Otras: irritabilidad, cólico abdominal (definido como dolor, quejido e irritabilidad por lo menos 3 horas al día, 3 días de la semana en un período mayor de 3 semanas).

En estos casos mantener lactancia materna con dieta de eliminación de proteínas lácteas a la madre, con suplemento de calcio (idealmente citrato de calcio, descartando el uso de gluconato de calcio), por dos semanas que se aumenta a cuatro en los casos de dermatitis atópica o colitis alérgica (deposiciones líquidas con mucus y/o sangre).

Si el paciente mejora durante la dieta de eliminación, realizar contraprueba reintroduciendo los lácteos en la dieta materna duran- 
te una semana, si los síntomas no reaparecen considerar que no existe alergia a la proteína leche de vaca.

Si los síntomas reaparecen al realizar la contraprueba los lácteos deben ser eliminados de la dieta materna mientras se esté amamantando. En el caso de destete utilizar una fórmula láctea altamente hidrolizada. La madre con dieta de eliminación prolongada debe recibir consejo nutricional.

Iniciar sólidos cocidos a los 6 meses de edad, siendo cuidadosos de no aportar alérgenos a los que el lactante pueda tener alergia. Los sólidos deben ser libres de proteína láctea hasta los 12 meses de edad y al menos durante 6 meses después de realizado el diagnóstico.

$\mathrm{Si}$ al realizar la contraprueba los síntomas atribuibles a alergia no se presentan, indicar a la madre dieta normal y realizar seguimiento continuo por si reaparecen los síntomas.
Por otro lado, si al someter a dieta de eliminación a una madre de un lactante con síntomas leves a moderados sugerentes de APLV el paciente no mejora, derivarlo al gastroenterólogo pediátrico.

\section{b) Sospecha de APLV severa con uno o más de los siguientes síntomas}

- Gastrointestinal: mal incremento pondoestatural (por diarrea, regurgitaciones o vómitos), rechazo alimentario, rectorragia con baja en la hemoglobina y/o enteropatía perdedora de proteína.

- Piel: dermatitis atópica severa asociada a mal incremento pondoestatural.

En estos casos se debe derivar al gastroenterólogo o dermatólogo pediátrico e iniciar dieta de eliminación a la madre con suplementación de calcio (figura 1).

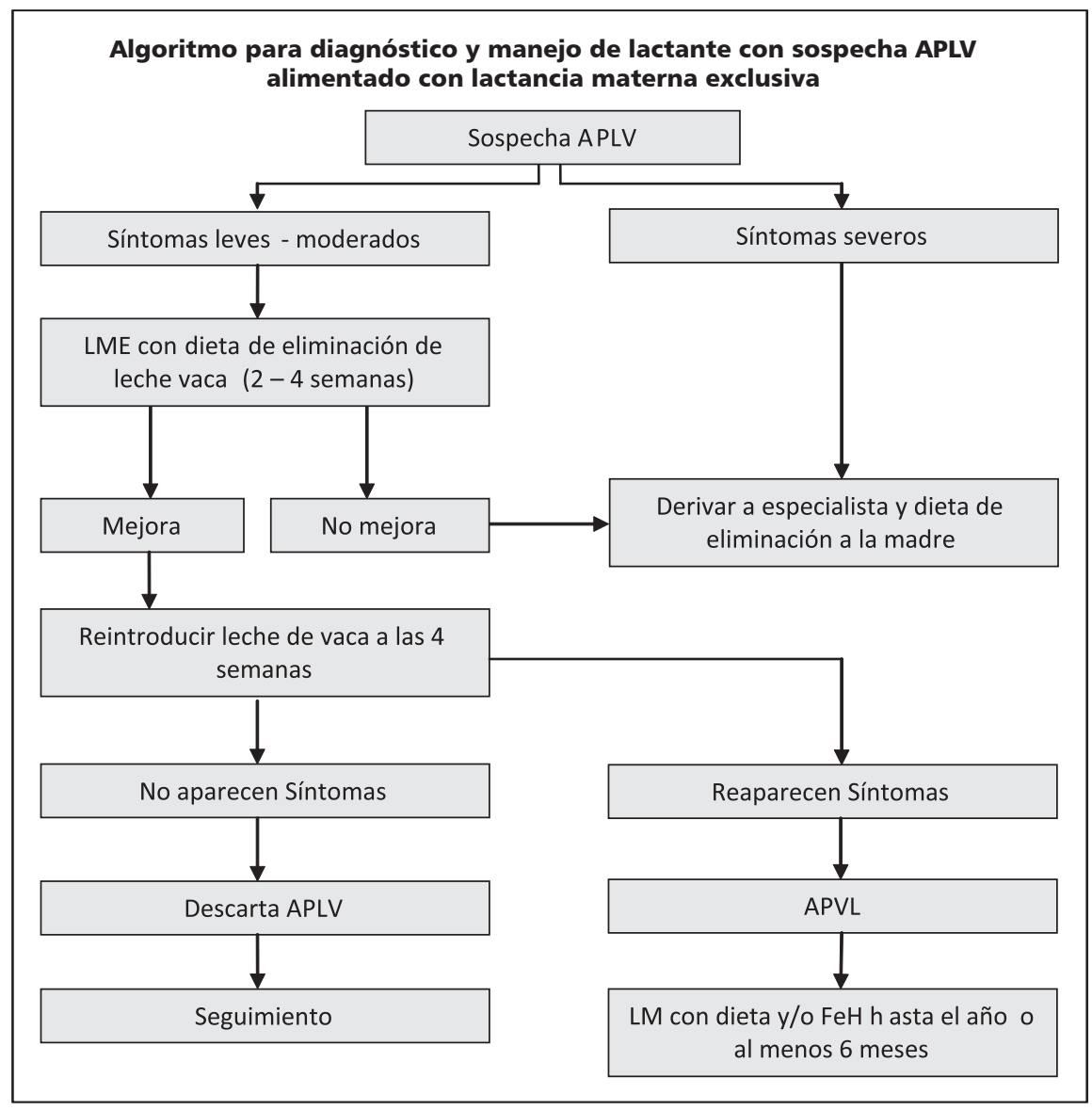

Figura 1. Algoritmo para el diagnóstico y manejo de la alergia proteína leche de vaca (APLV) en lactantes menores de un año alimentados con leche materna exclusiva (LME); LM = Lactancia materna; $\mathrm{FeH}$ = fórmula extensamente hidrolizada. 


\section{Sospecha de APLV en niños alimentados con formula}

Al igual que los niños alimentados al pecho se debe realizar una historia clínica y examen físico detallados con énfasis en los antecedentes de atopia familiar o personal. Además se podría considerar según disponibilidad estudio con test cutáneo especifico para leche de vaca.

\section{a) Sospecha de APLV leve o moderada con uno o más de los siguientes síntomas:}

- Gastrointestinal: regurgitaciones frecuentes, vómitos, diarrea, rectorragia constipación (con o sin eritema perianal).

- Piel: dermatitis atópica.

- Respiratorio: Rinitis, tos crónica, sibilancias no asociadas a infecciones.

Si el lactante presenta alguna de estos síntomas se debe indicar fórmula altamente hidrolizada (con proteína de suero, caseína u otra) o una fórmula basada en aminoácidos. Si el paciente no mejora después de 2 a 4 semanas de dieta de eliminación derivar al especial

Si se observe mejoría realizar contraprueba abierta con leche de vaca bajo observación médica. Si en la contraprueba no presenta síntomas de alergia reiniciar proteína láctea en la dieta y realizar seguimiento. Si el lactante alimentado con fórmula con síntomas leves a moderados no mejora y ha usado formula extensamente hidrolizada probar dieta de eliminación con fórmula basada en aminoácidos. Al realizar el diagnóstico de APLV mantener la dieta de eliminación hasta los 12 meses o al menos 6 meses después de realizado el diagnóstico

\section{b) Sospecha de APLV severa con uno o más de los siguientes síntomas}

- Gastrointestinal: mal incremento pondoestatural (por diarrea, regurgitaciones o vómitos), rechazo alimentario, anemia ferropriva secundaria a sangrado digestivo macro o microscópico, enteropatía perdedora de proteína (hipoalbuminemia) y enteropatía o colitis alérgica severa confirmadas por endoscopia e histología.

- Piel: dermatitis atópica severa con hipoalbuminemia, anemia y mal incremento ponderal.
- Respiratorio: edema laríngeo agudo u obstrucción bronquial.

- Shock anafiláctico.

En estos casos severos derivar al especialista e iniciar dieta de eliminación con fórmula basada en aminoácidos. Los test de provocación en estos pacientes deben realizarse bajo estricta observación médica (figura 2).

Por otra parte, el uso de leches de otros mamíferos como: vaca no modificada, oveja, cabra, búfalo, caballo o leche no modificada de soya o arroz no se recomienda para niños menores de un año, ya que no cubren los requerimientos nutritivos y existe el riesgo de reacciones alérgicas cruzadas ${ }^{11,12}$. Se han reportado reacciones adversas a soya en una 10-35\% de los lactantes menores de un año con APLV ${ }^{13}$.

\section{Confirmación diagnóstica}

En la mayoría de los casos el diagnóstico de APLV se basa en la sospecha clínica y la respuesta del paciente a la exclusión de la dieta del presunto alérgeno. Idealmente este tipo de intervención empírica debe ser confirmada mediante una prueba de provocación, para remedar la sintomatología ante la reintroducción del alérgeno.

El método de referencia (gold standard) es la prueba comparativa a doble ciego contra placebo (DBPCC) para evitar los efectos de tipo placebo o la interpretación subjetiva de tolerancia o recaída ${ }^{14}$. Sin embargo, en la práctica clínica cotidiana, salvo casos muy específicos asociados a cuadros graves, el enfrentamiento se realiza como provocación abierta, es decir, que tanto el paciente (o su familia) como el médico tratante están al tanto de la reintroducción de la proteína alergénica ${ }^{8}$.

Para realizar la provocación, el ámbito (ambulatorio u hospitalario) y la intensidad de la carga alergénica (forma progresiva o rápida) se deben ajustar al tipo de sintomatología del paciente. Es recomendable que en los cuadros moderados y graves, con sintomatología sistémica, o en aquellos con sospecha de posible reacción anafiláctica, las pruebas se realicen en un hospital y con reintroducción 




Figura 2. Algoritmo para el diagnóstico y manejo de la alergía proteína leche de vaca (APLV) en lactantes alimentados con fórmula. progresiva y controlada del alérgeno, mientras que en los cuadros leves la provocación se suele realizar en forma ambulatoria y con dosificación más rápidamente creciente ${ }^{15-17}$.

En casos seleccionados y de excepción frente a una sospecha de reacción mediada por IgE solicitar IgE específicas a leche y sus fracciones y/o pruebas cutáneas de hipersensibilidad inmediata (prick test). Frente a sospecha de reacciónmediada por células solicitar prueba de parche.

\section{Referencias}

1.- Fiocchi A, Brozek J, Schünemann H, et al: World Allergy Organization (WAO) diagnosis and rationale for action against cow`s milk allergy (DRACMA) guidelines. WAO Journal 2010; 57-161.
2.- Orsi M, Fernández A, Follett F, et al: Alergia a la proteína de la leche de vaca. Propuesta de guía para el manejo de los niños con alergia a la proteína de la leche de vaca. Arch Argent Pediatr 2009; 107 (5): 459-70.

3.- Saarinen KM, Juntunen-Backman K, Järvenpää Al, et al: Supplemenary feeding in maternity hospitals and the risk of cow`s milk allergy. Prospective study of 6209 infants. J Allergy Clin Immunol 1999; 104: 457-61.

4.- Kvenshagen B, Halvorsen R, Jacobsen M: Adverse reactions to milk in infants. Acta Paediatr 2008; 97: 196-200.

5.- Arroll B, Pert H, Guyatt G: Milk allergy and bottles over the back fence: two single patient trials. Cases $\mathrm{J}$ 2008; 1: 77-8.

6.- Bahna SL: Diagnosis of food allergy. Ann Allergy Asthma Immunol 2003; 90: S77-80.

7.- Björkstén B: Genetic and environmental risk factors for the development of food allergy. Curr Opin Allergy Clin Immunol 2005; 5: 249-53. 
8.- Vandenplas Y, Koletzko S, Isolauri E, et al: Guidelines for the diagnosis and management of cow's milk protein allergy in infants. Arch Dis Child 2007; 92: 902-8.

9.- Saarinen UM: Breastfeeding as prophylaxis against atopic disease: prospective follow-up study until 17 years old. Lancet 1995; 346 (8982): 1065-9.

10.- Høst A, Halken S, Jacobsen HP, Christensen AE, Herskind AM, Plesner K: Clinical course of cow's milk protein allergy/intolerance and atopic diseases in childhood. Pediatr Allergy Immunol 2002; 13 (Suppl 15): 23-8.

11.- Restani P, Gaiaschi A, Plebani A, et al: Cross reactivity between milk proteins from different animal species. Clin Exp Allergy 1999; 29: 997-1004.

12.- Spuergin P, Walter M, Schiltz E, Deichmann K, Forster $J$, Mueller $H$ : Allergenicity of a-caseins from cow, sheep, and goat. Allergy 1997; 52: 293-8.

13.- Klemola T, Vanto T, Juntunen-Backman K, Kalimo K, Korpela R, Varjonen E: Allergy to soy formula and to extensively hydrolyzed whey formula in infants with cow's milk allergy: a prospective, randomized study with a follow-up to the age of 2 years. J Pediatr 2002; 140: 219-24.

14.- Chapman JA, Bernstein L, Lee RE, et al: Food allergy: a practice parameter. Ann Allergy Asthma Inmunol 2006; 96: 1-49.

15.- Niggemann B, Beber K: Diagnosis of food allergy in children: toward a standardization of food challenge. J Pediatr Gastroenterol Nutr 2007; 45: 399-404.

16.- Caffarelli C, Baldi F, Bendandi B, Calzone L, Marani $M$, Pasquinelli $P$ : Cow's milk protein allergy in children: a practical guide. Italian Journal of Pediatrics 2010; 36: 5-11.

17.- Boyce J, Assa'ad A, Burks A: Guidelines for the Diagnosis and Management of Food Allergy in the United States: Report of the NIAID-Sponsored Expert Panel. J Allergy Clin Immunol 2010; 126 (6) S1-58. 